\title{
SEMIOLOGIC CONSIDERATIONS ON MAN-MADE ENVIRONMENT
}

\author{
-Part One--
}

\author{
by MANFRED SPEIDEL, Member of A.I.J.
}

In recent years quite a few investigations in architecture were dedicated to study the subject from the view of a semiology. Especially some Italian theorists (see bibliography) were fun of applying the theories of the fathers of semiotics (OGDEN and RICHARIDS, CH.W. MORRIS) as well as the studies of the structuralists (LEVI-STRAUSS, BARTHES) to problems of communication by and in architecture. In Germany Max BENSE from the early 1950's on emphasized the sign-character of art objects and developed an information-aesthetics out of this premiss; Elisabeth WALTHER investigated in to the theory of signs in CH. S. PEIRCE's Collected Papers and applied it first to texts of Francis PONGE. I myself took lectures and seminars with both BENSE and WALTHER (in Stuttgart).

Recently semiotc problems caught the interest of dialectic-materialist philosophers (Adam SCHAFF, Poland; L.O. RESNIKOV, Russia), and it seems to have opened up a door to a wide range of basic investigations in the theory of science, cybernetics, logics and politics with the excellent treatises of Georg KLAUS (East-Berlin).

As contributions from researches in architecture, yet without a comprehensive theory, there is in Japan a "Waseda School" with the Minka-ron of W. KON, and Yukeigaku of T. YOSHIZAKA, and an "American Shool" : Psychosomatic aspects of architecture in R. NEUTRA's theories, K. LYNCH's, "Image"-investigations, congruency theories (STEINITZ), behavioral setting (P. GUMP), territorial behavior (E.T. HALL), envirotecture (Ph. THIEL), and then applications of communication and information theories (R.L. MEYER, A. RAPOPORT and R. HAWKES, and M. KIEMLE in Germany).

\section{Triadic Relations in Communication Processes.}

For man the main means of communication is language. Any other communicational means-insofar as they are conventions-are replacement of words or sentences for special purposes (the visual fingeralphabet for the deafs; flagsignals for large distances (visual), gestures as valid for a specific culture; arrangement of spaces and places in some primitive communities; etc), and they require instructions or dictionaries for the process to learn their contents and to use them. These signsystem can be regarded as "incomplete", i. e. to be completed by language, if they are intended to "inform".

Feelings and actions are reflected upon in thought or speech, special skillful actions are demonstrated and taught; dreams become symbolic under psychoanalytic work in which the patient develops connotations and denotations from their contents by associative speech.

On the other hand, if words are intended to regulate or evoke action they have to be accompanied (or completed) by an actual context of things on which the action can take place.

If something is intended to be remembered, to be stored in the memory not under pressure (as in

school learning) but because it is worth or nice, it will have to be presented in impressive pictures, may it be erotic or else affective, as a pin-up girl on an automobile foto, or as a theme melody, or an "incorporate image" for a company.

We are going to note these interrelations in a diagram consisting of three members: $I$, an interpreting faculty (a user, a consumer, a producer); $O$, the objects of his concern (his 1 . environment), and $\mathrm{S}$, the signs, symbolic presentations, he employs to communicate (his 2 . environment). The interrelationship of the three members can be said to represent a generalized system of environment 
and can be subdivided into the following parts (see figure 1) :

1.1 Triadic systems within the organism itself: $(\mathrm{I} ;(1,2,3))$.

A) Built-in schemes resulting in unconditioned reflexes (autonomous nervous system)

B) "Inner perception", i. e. the psychoanalytic notion of "symbol". (1) Ego is understood as form-giving, symbol-producing faculty out of stimuli (2) resulting in dreams and fantasies (3) (the dreams have to be analysed, i. e. their object has to be determined, otherwise it doesn't become "symbolic"). The stimuli-sources are a) outerworld $(\rightarrow 1.2)$ and bodyprocesses, b) impressions remaining from the actual experiences of the day and subliminal influences (storage in nervous system), c) the stored images in the memory, and d) the structured reservoire of the unconscious ${ }^{2}$.

1.2 Triadic systems between interpretant and object-world : $(I, 0(4,5))$. Information extraction from the environment

A) resulting in immediate responses (unconditioned and conditioned reflees. E.T. HALL's Primary Message systems ${ }^{2}$,

B) giving material for the storage (images, correlations, etc),

C) Information extraction may be based on the realization of contexts:

a) causal contexts : members of environmental objects appear in uniform contiguity (smoke $\rightarrow$ fire).

b) cultural contexts : purposefully made objects form sets and have a use-context (set of dishes $\rightarrow$ food).

In either case inference processes (associations) take place from a part of the context to the rest or to the whole $\cdot(4) \rightarrow(5)$

1.3 Triadic systems between interpretant, objects and signs: $(1,0, S)$, which are employed to represent an object, $\mathrm{O}$, i. e. an object which is not at hand. Environmental elements may be used as well as other made objects, pictographs, words (a picture of a tree representing a tree; a way-sign leading to a town, a torii marking the entrance to a shrine, .....)

1.4 Triadic systems between interpretant and sign-systems : $(I, S(6,7))$

which represent concepts or other signs(S.K. LANGER's "discursive" and "presentational" symbols). The inner, structural laws of the symbolsystems become very dominant.

1.3 and 1.4 belong to the "Secondary Message Systems" (HALL) which have the function to delay responses. They evoke images, fantasies, thoughts in I.

1.5 Communication between at least two interpretants using signs as media (words, gestures, stimuli evoking body-changes) may be also considered as triadic systems where the object of communication is not the contents of the signs but the partner, whose reactions again can be object of reflexion.

For an architectural semiology all of the sub-systems are of interest insofar as some instrumental or some reflectional function is connected with it.

The term "triadic relation" stems from Charles Sanders PEIRCE who uses it to denote logically what happens psychologically in the process of thinking. PEIRCE admits that there are "lower" levels of processes than thinking which he names interpretants as feeling and interpretants as action, or as we might understand it psychologically as associational responses which affect the autonomous nervous system and as immediate effector responses.

In figure 1 we try to combine them in a system-notion of triadic relations to demonstrate the possible interconnectedness of the different processes. $\leftarrow$ means a direct, physical

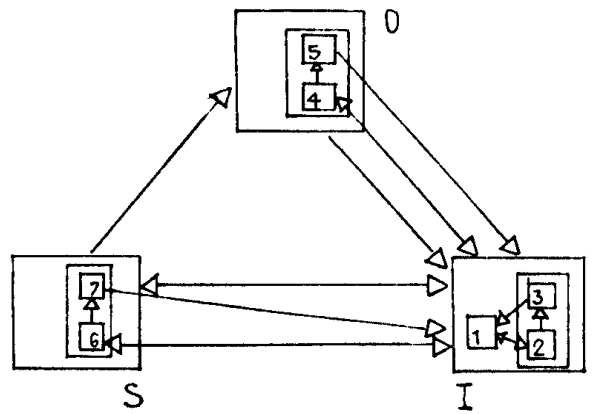

Fig. 1 Triadic systems between Sign, Object and Interpretant 
connection; $\rightarrow$ means an imputed or associational connection.

\section{Triadic System (I, S, O) and the Sign-Graduator.}

Now we proceed to show conditions in 1.3 , i. e. in representational signs which may be constituted by pictures, environmental forms, or words (names, characters, etc) which we understand here as reductions (or the extract) from ordinary, grammatically bound speech, and develop along PEIRCE's lines a graduation model which shows the interconnectedness of triadic systems of the type 1.3 with those of the associational type of 1.2 , i. e. representation of environment along its observation and use.

2.1 Three Ontological Planes ${ }^{3}$.

Ch. S. PELRCE developed a graduation scheme for signs under the aspect of their degree of independency.

In his phenomenology the first level (or Firstness) is that of a possibility, of material qualities, and is the most independent. The third level (or Thirdness) is the level of laws and rules, the level of reason, and is the most dependent. Laws are extracted as common features from events, and have therefore on the other hand to be realised in actual examples or singular events (the second level or Secondness), and singular events in turn are embodied in material qualities (Firstness). So the interdependency is that Thirdness depends on Secondness and Firstness and Secondness depends on Firstness. According to these conditions there exist three interdependent levels of signs.

2. Formal Properties of Signs and Sign-Relations. (acc. to PELRCE)

2.1 A sign may be difined by its own character :
a) as its material aspect
Quali-sign (from : quality)

Firstness

(having some quality, sense-perceptual properties e. g. the shrill sound of a locomotive as being felt)

b) as its space-time aspects Sin-sign ( $\sin =$ singular)

Secondness (a physical event, a singular, individual event : the actual taking place of the whistle)

c) as its gestalt aspects

Legi-sign $($ lex $=$ law $)$

Thirdness (constituting an abstraction-class, a law according to which the various individual signs are recognized as the same type of sign : whistle at a crosspoint means : "take care!", it is a type of warning signal)

2.2 A sign may be defined by the form of representation of its object : $R(S, O)$

a) if the relation is one of similarity

iconic

b) if the relation is one of contiguity

indexicalic

c) if the relation is one of convention involving concepts

symbolic

a) Iconic, when the sign employs similarity properties to demonstrate its relation to its object, i.e. when it has some kind of similarity with its object (e.g. in form, colour, size, direction, etc). The sign-user has to recognize these similarities, i. e. the association must be done upon the properties of the icon itself. If this is not possible the sign is unintelligible or has to become a sign of pure convention.

(any kind of structural similarity evoking a similar image in I, e. g. pictures standing for an object : a picture of a tree on a map.

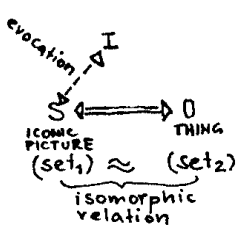

b) Indexicalic, if the relation of the sign to its object is one of contiguity, if $S$ is a part of a (uniform) context with $\mathrm{O}$, so that by seeing $\mathrm{S}$ the interpretant may infer to the rest of the context which might be not present.

(any kind of contiguity relation, which might be also a cause-and-effect relation, independent of $I$, but in which $I$ is inferring from the cause to the effect, e.g.

sound $\rightarrow$ locomotive,

smoke $\rightarrow$ fire,

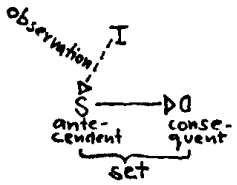

a map as a space-indicator to find the tree.) 
c) Symbolic, if the relation of the sign to its object is only to be realized by an idea of the interpretant, by his establishing the relation, and a convention : by an arbitrary selection, or by development of traditioned images.

(any kind of imputed relation established by I, e. g. the chemic formula of the organic substance of a tree, but also the term "tree" to denote that thing. In the 1 . case a concept is involved, in the 2. a convention.)

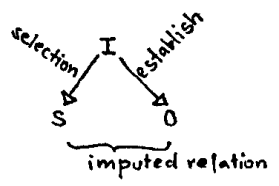

2.3 A sign may be defined by the structure of the effect on its interpretant : $R$ (S, I)
a) if the relation is one of similarity
rhematic
b) if the relation constitutes a sequence
dicent
c) If the relation determines a rule
argument

a) rhematic, if the influence is open, rather unfixed, open to associations, evoking images-as e. g. by a single word establishing moods : "Oh, wonderful!",

b) dicent, if the influence is such that some relation to the reality may be established, that inference is possible from an "antecedent" to a "consequent"as is most part of daily talk and information-as in following a path and finding the goal-prerequisite to the performance of an action : sequences of acts, the actual observation of a tree.

c) argument, if in addition there can be found or given a rule or "principle of sequence"-as in scientific talk, a conception determining some principles, some reasoning, e. g. the rules of games, reasons why to play it best that way, etc. :

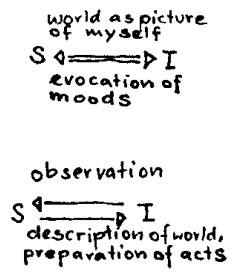

Motivations. A scientific discussion on the process of organic matter in the tree.

\section{10 Classes of Signs.}

A sign can only be considered as a combination (or collaboration) of its three basic factors : sign itself, the form of representing its object and the structure of its influence on its interpretant, or the combination of $\mathrm{S},(\mathrm{S}, \mathrm{O}),(\mathrm{S}, \mathrm{I})$, in their way of determining each other, or as PEIRCE insists to say that the triadic relation must be genuine, that is, it cannot be divided into any dyadic relations.

We now have to consider the interrelatedness of the three factors and the classes they constitute in combination.

3.1 For a sign to be a physical event (sin-sign) material quality is prerequisite (quali-sign). A rule (legi-sign) can only be established if there are real events from which the rule may be abstracted. So a legi-sign requires examples (sin-signs) as applications for its law-properties (but not reverse) and examples need to be materialized (to be experienced) :

$\mid \frac{\text { Quali-sign }}{\frac{\text { Sin-sign }}{\text { Legi-sign }}}$

graduation of the sign-realisation,

3.2 Icons can be used independently; they have their own formproperties which may conver an information.

Indices can be used only together with objects (or names of objects), or if the object is absent (or if it is unknown), an icon is to be used instead.

Symbols can be used independently (but only for operational purposes);

\begin{tabular}{|c|}
\hline Icon \\
\hline Index \\
\hline Symbol \\
\hline
\end{tabular}
for a reference to real events a real object has to be shown or, if not available, an index instead. For the representation of the absent object a proper icon is needed which demonstrates its properties.

graduation of the symbol-niveau. ${ }^{1}$

3.3 As the interpretant takes the sign (not its object), rules and reasoning (arguments) have to be applied in a performance or the sequence of a performance has to be layed down (dicent). Any prescription of a sequence involves images of the parts of its elements (rheme) :

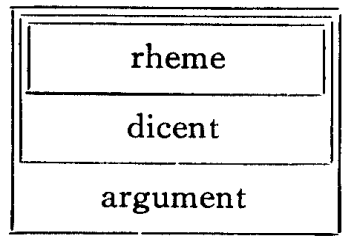

graduation of the sign-effect.

3.4 The form of representation ( $\mathrm{S}, \mathrm{O}$ ) depends largely on the own character of the sign, (S), and 
the effect on the interpretant ( $S, I)$ depends largely on the form of representation (S, O), or as PEIR$\mathrm{CE}$ insists : the third member $(\mathrm{S}, \mathrm{I})$ of a triadic relation is always somehow determined by the second member $(\mathrm{S}, \mathrm{O})$, which again is determined by the character of the first member (S). We get another order of interrelations between the three factors of a sign-relation.

The combination of these members results in 10 classes of signs : the lines show the possible combinations between the elements.

4. The Sign-Graduator (see figure 3)

4.1 The hierarchic ordering of the factors Fig. 2

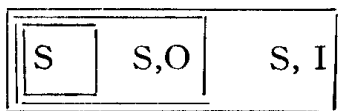

the sign-relations result in the combination of ten classes of signs. As we understand it here the main importance is not the subtle classification of signs resulting in monstruous names but the possibility to manipulate signs of various degrees of abstractness in contexts of real situations (such as cartraffic, or the events of an Expo or Olympic games). So our sign--operator defines the degree of abstractness as well as the interrelations of the ten classes.

Each class thus is characterised

a) by its position between 1 and 10. Its position gives its degree of abstractness or on the other side its closeness to reality from the standpoint of the interpretant, i. e. from the standpoint of its extracting and processing information.

1 is then the most "concrete", the most independent class, and 10 the most abstract, the most distant from reality.

b) by the number of lower classes involved to demonstrate the connection with reality and to demonstrate the level of processing in the interpretant.

So class Nr. 10 general symbols for arguments" need 5 lower classes of signs to be pinted down to the kind of real existing event it is intended for : $i$. e. the connection to reality has to be shown by indices and icons, and the usefulness for the interpretant by dicentic and rhematic effects. In the $\mathrm{R}(\mathrm{S}, \mathrm{O})$ column the lower sign classes have the purpose to indicate the object e. g. as a real existing thing by indices (fixing its extension), and to explain the symbols meaning-to show the properties of the object-by means of iconic descriptions (fixing its intension).

4.2 Now we can discuss some positions in the sign-graduator as follows:

4.21 The interpretant can become an argument (a scientific, or any kind of other conceptual understanding) only when the object is represented symbolic and when the Interpretant's images and performances are unified in a logic picture. By using only indices the interpretant may find the object, may conduct observations (dicentic) or only be stimulated to a feeling; by means of icons the interpretant can only catch an idea, a mood and only so much as the icon reveals to him.

$4.22 \mathrm{~A}$ big problem for graphic design is what kind of iconic pictures are suitable for indices and for symbols (see the international movement to create iconic pictographs for events like an Expo or Olympic Games). We will come to this point in the next paper.

4.23 One kind of reactions towards pictographs designed by graphic designers (like the "Ulm$\left.\mathrm{ers}^{\prime \prime}\right)$ is the people's mistaking them for art objects, i. e. they don't recognize them as signs standing for a building, a situation or a function, etc. but looking at them simply as pictures.

It is an ordinary use in advertising to mix these two spheres, i. e. the sphere of information with the sphere of association by affective pictures.

PEIRCE's sign-graduator reveals this problem by his notion of Replicas. Replicas are the materialized copies, the realized instances of the Legi-signs. The Legi-signs are (as an abstraction class) the sign-gestalts, whereas the replicas are sign-examples such as a copy taken from a stencil.

According to the sign-graduator: the 6 Legi-signs (class 5 to 10) result in only 3 types of Replicas: 


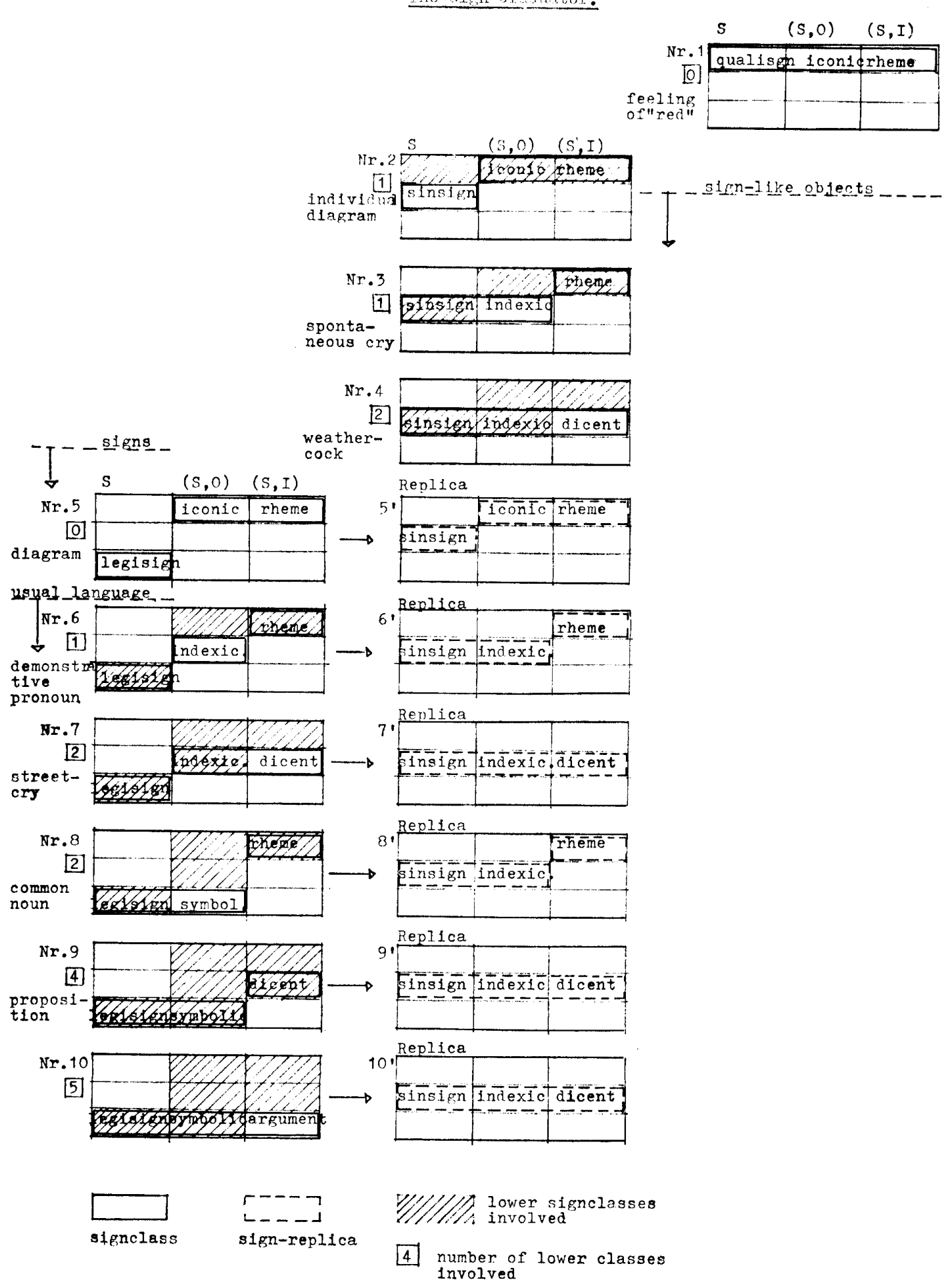

Fig. 3 Ten Classes of Signs acc. to Ch. S. Peirce (2.642). The Sign-Graduator

a) it is difficult to decide to which kind of sign-class a replica may belong, and

b) the Replica might be mistaken for one of the Sin-signs (class 2 to 4) to which they resemble.

Art objects which are singular, e. g. visual events belong to one of the 3 Sin-sign classes. So it happens that graphic signs-especially when they appear abstract and in nonrealistic colours-may be mistaken for colour-compositions instead of marking a coffeeshop, or a toilette, or a way.

4.3 For the use of the sign-graduator as a tool we have to know the character of the object (real thing, class, or concept), and we have to determine the interpretant. 
If the aim of our sign-system is e. g. the effect towards a real event or a set of actions of the interpretant, he will have to become a dicent, and all signs have to be determined to realize the conditions of dicents (9., 7.,4. class), and have to be degenerated from higher classes or generated from lower ones. This will be demonstrated in another paper on the Olympic Games facilities in Muenchen.

\section{Reference}

1) Alfred Lorenzer, Kritik des psychoanalytischen Symbolbegriffs, edition suhrkamp, Nr. 393, 1970.

2) Eslward T. Hall, The Silent Language, Premier Book, Nr. R 204, 1968.

3) Charles Simders PEIRC 'l Collected Papers. 2,243-264 Cambridge, Mass. 1931-1935 